\title{
A New Binder Mineral for Cement Stabilized Road Pavement Soils
}

\author{
Aydin Kavak, Özkan Coruk, Adnan Aydiner
}

\begin{abstract}
Long-term performance of pavement structures is significantly impacted by the stability of the underlying soils. In situ subgrades often do not provide enough support required to achieve acceptable performance under traffic loading and environmental demands. NovoCrete ${ }^{\circledR}$ is a powder binder mineral for cement stabilized road pavements soils. NovoCrete ${ }^{\circledR}$ combined with Portland cement at optimum water content increases the crystallize formations during the hydration process, resulting in higher strengths, neutralizes $\mathrm{pH}$ levels, and provides water impermeability. These changes in soil properties may lead to transforming existing unsuitable in-situ materials into suitable fill materials. It can be used also for stabilization of recyclable aggregates and old asphalt pavement aggregate, etc. In the road construction works, this binder material is used for cement stabilization works. In the applications usually $120-180 \mathrm{~kg}$ cement is used for 1 $\mathrm{m}^{3}$ of soil with a $2 \%$ of binder NovoCrete $\AA$ material for the stabilization. The results of a plate loading test in a road construction site shows $0,7 \mathrm{~mm}$ deformation which is very small under $7 \mathrm{~kg} / \mathrm{cm}^{2}$ loading. The modulus of subgrade reaction increase to $1322 \mathrm{MN} / \mathrm{m}^{3}$ and $1666 \mathrm{MN} / \mathrm{m}^{3}$. The soaked CBR values for stabilized soils increase from 15-22 \% to 224-239 \%. According to these data and methods, weak subgrade soil can be used as a base or sub base after the modification. The potential reduction in the need for quarried materials will help conserve natural resources. The use of on-site or nearby materials in fills, will significantly reduce transportation costs and provide both economic and environmental benefits
\end{abstract}

Keywords-- soil, stabilization, cement, binder, NovoCrete ${ }^{\circledR}$, additive

Aydın Kavak

Department of Civil Engineering, Faculty of Engineering, Kocaeli University, Geotechnics Division, Turkey

Özkan Coruk

Department of Geology Engineering, Faculty of Engineering, Kocaeli UniversityTurkey

Adnan Aydiner

Jags innonative products,

Turkey

\section{Introduction}

In the study, the effect of cement and mineral (Novocrete $\left.{ }^{\circledR}\right)$ blend strength properties on geotechnical properties of grained soils such as sand, gravel or clay is investigated. Short and longterm performance of pavement structures is significantly impacted by the stability of the underlying soils. In situ subgrades often do not provide the support required to achieve acceptable performance under traffic loading and environmental demands. When the performance of the road material in the site is not suitable for road construction, borrow material is needed which is dredged from nearby river or mined from surrounding pits. Instead of using borrow material; it may be more economical to use in situ soil provided that the performance criteria are met. Improvement of the existing soil reduces the need for cut and fills works, minimizing the environmental impacts.

Soil stabilization occurs when additives are added to a reactive soil to generate long-term strength gain through pozzolanic reactions. There are many stabilization additives for the soil improvement that are widely used in the world. For stabilization of various types of soils; cement, lime, slag, fly ash and various special chemicals were used widely as additives for improvement of fill layers of foundations or highway embankments (1), (2), (3), (4). These are an economical method to avoid the more expensive process of transporting in large quantities of granular earth fill.

These variations necessitate the consideration of site-specific treatment options which must be validated through testing of soil-stabilizer mixtures. This report addresses soil treatment with the special mineral blend type Novocrete ${ }^{\circledR}$, Portland cement, water and soil. The construction and maintenance of highways creates a demand for high quality paving aggregates, which are becoming scarce in many parts of the world considering the scarcity of fresh aggregate, replacement of part of the fresh aggregate with recycled aggregate or evolving at suitable mineral blended and cement blended stabilized soil subgrade based pavements is required to be evaluated.

Sulieman et all.(5) studied the environmental effect of Novocrete material which plays a significance part at buildings and roads becomes a 
new material that wasn't studied before. The optical properties that have been examined by both Fourier Transform Infra-Red FTIR and Ultra Violet $U V$ showed the bonds and energy band gap; the energy gap value and the multi bonds indicate that the material is insulator and the impedance spectroscopy results confirm the behavior. For environmental issue the material can be classified as an environment friend, the reason is coming from the Novocrete material elements. NovoCrete ${ }^{\circledR}$ combined with Portland cement at optimum water content increases the crystallize formations during the hydration process, resulting in higher strengths, neutralizes $\mathrm{pH}$ levels, and provides water impermeability. These changes in soil properties may lead to transforming existing unsuitable in-situ materials into suitable fill materials. The main features of NovoCrete $\AA$ are: They are applicable to all types of soil, reduce premature cracking and improve soil properties, creating base and subbase course layers with high bearing capacity by reducing hazardous materials.

In this study, a real application was conducted on a part of divided road project constructed a few years ago around Ankara city Turkey. The laboratory and field tests shows that the material modified by cement and binder had an excellent performance under the high stresses.

\section{Methodology}

In the present study, typical ordinary Portland cement was selected and used. NovoCrete ${ }^{\circledR}$ is a powder binder mineral used as an additive for Portland cement. NovoCrete $\AA$ combined with Portland cement and optimum water content increases the crystallize formations during the hydration process, resulting in higher strengths, neutralizes $\mathrm{pH}$ levels, and provides water impermeability. NovoCrete $₫$ is an environmentally friendly mineral and is $100 \%$ recyclable. Key features of Novocrete are: They are applicable to all types of soil, reduce premature cracking and improve soil properties, creating base course layers with high bearing capacity by reducing the premature cracking, stabilization and immobilization of hazardous materials in one step.

In this study, a real application was conducted on a part of divided road project constructed a few years ago around Ankara city Turkey. The existing road had many deformations on the surface and necessitates reconstruction. The road was modified at a thickness of $40 \mathrm{~cm}$ from the surface by using cement and Novocrete additive in site without replacement the soil. Cement amount used in the rehabilitation project was $143 \mathrm{~kg}$ for $1 \mathrm{~m}^{3}$ of soil and Novocrete amount was $2.86 \mathrm{~kg} / \mathrm{m}^{3}$ which one is $1 / 50$ of the cement amount in the mixture. Initially the geotechnical properties of the granular existing road material were determined in the laboratory. Atterberg limit tests, grain size analysis, standard and modified Proctor compaction tests and soaked California Bearing Ratio $(C B R)$ tests were conducted to define the typical geotechnical properties of the existing material. The tests were conducted with the proposed amount of cement and binder materials and the results were compared to each other.

\section{Laboratory and Field tests}

\section{A. Grain size Distribution of the materials}

The sieve analysis tests were conducted and particle size distribution is drawn and is shown in Fig. 1.

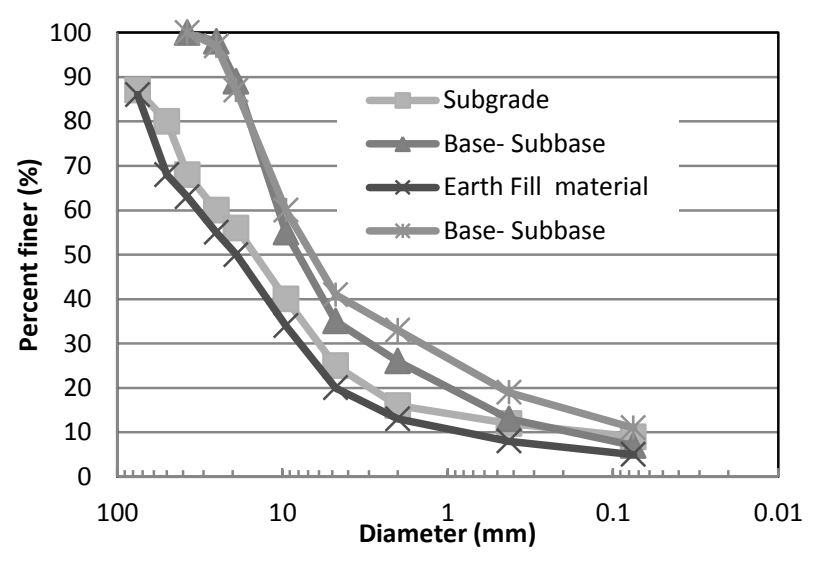

Fig.1 Grain size distribution of the materials

Four specimens were taken from the existing road and sample 2 and 4 were stabilized with lime and Novocrete material.

\section{B. Typical soil properties}

Atterberg limit tests were conducted for the soil samples taken from the existing road. Stabilized samples which are numbered as two and four had non-plastic properties. The original materials have a plasticity index 12 and $13 \%$. The tests were conducted in accordance with ASTM 4318 (6).

Modified and Standard compaction tests were performed to obtain compaction characteristics of all the materials. The tests were conducted according to the ASTM D 698-78 and D 1557-78 (6). Under light compaction (i.e. standard Proctor) the soil achieved a maximum dry unit weight of 19.3 and $20.3 \mathrm{kN} / \mathrm{m}^{3}$ at an optimum moisture content of 11.9 and $9.4 \%$. The soil attained a 
maximum dry unit weight of 22,8 and $22.6 \mathrm{kN} / \mathrm{m}^{3}$ at an optimum moisture content 5.1 and $5.4 \%$ under heavy compaction for stabilized samples.

TABLE I. TYPICAL GEOTECHNICAL PROPERTIES OF THE MATERIALS

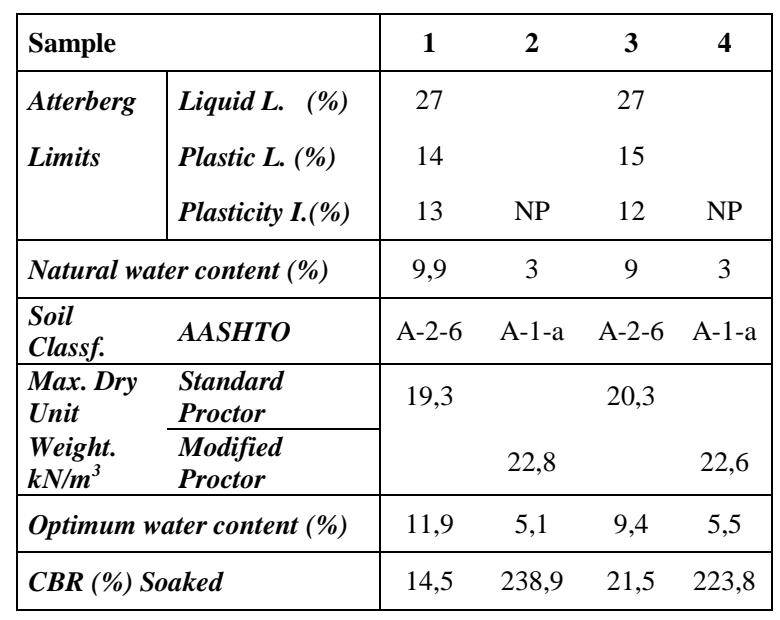

A series of laboratory soaked $C B R$ tests for the materials were performed on samples moistcompacted at its maximum dry unit weight and optimum moisture content at heavy compaction. California bearing ratio tests were conducted according to the ASTM D 1883-87 (6). Under soaked conditions the CBR value of natural soil is 14.5 and $21.5 \%$ at light compaction. After modification with cement and Novocrete, the soaked (for 4 days) $C B R$ values increase and reaches to 224 and $239 \%$ which are very high values compared to classic road earth fill materials.

\section{Plate Loading Tests}

Plate loading tests were conducted in the field over the stabilized surface area with a plate of 30 $\mathrm{cm}$ in diameter. Two tests were conducted with two cycles of loading and unloading. First test is shown below in Fig. 2. There is maximum $0.7 \mathrm{~mm}$ elastic and $0.5 \mathrm{~mm}$ permanent deformations after two cycles loading. These are very small values compared to $690 \mathrm{kN} / \mathrm{m}^{2}$ stress $\left(6.9 \mathrm{~kg} / \mathrm{cm}^{2}\right)$. Second test is shown below again in Fig. 2. There is maximum $0.38 \mathrm{~mm}$ elastic and $0.2 \mathrm{~mm}$ permanent deformations after two cycles loading. These are very small values compared to $690 \mathrm{kN} / \mathrm{m}^{2}$ stress $\left(6.9 \mathrm{~kg} / \mathrm{cm}^{2}\right)$ and also less than to the first Plate loading test.



Fig. 2. Plate loading test 1

Elastic moduli found in the tests were 247 and $414 \mathrm{MN} / \mathrm{m}^{2}$ for the first loading and 446 and 819 $\mathrm{MN} / \mathrm{m}^{2}$ for the second $P L$ test. Deformation moduli found in the tests were 1.81 and 1.98 which shows the compaction is satisfactory. The modulus of subgrade reaction values were found very high and 1322 and $1666 \mathrm{MN} / \mathrm{m}^{3}$. All of these values are very high and good values for the road construction and modeling purposes.

\section{Unconfined Compression Tests}

Unconfined compression test was conducted on the soil samples prepared at optimum moisture content and maximum dry density for cylindrical specimens 15:12 in size. The strain rate was maintained at $1.25 \mathrm{~mm} / \mathrm{min}$. The specimens are prepared by mixing cement at an amount of 143 $\mathrm{kg} / \mathrm{m}^{3}$ and Novocrete amount was $2.86 \mathrm{~kg} / \mathrm{m}^{3}$ which one is $1 / 50$ of the cement amount in the mixture. The unit weights of the specimens are $22.7 \mathrm{kN} / \mathrm{m}^{3}$ and specimens were prepared at $6.5 \%$ water content.



Fig. 3. Unconfined compression test summary 
The prepared samples were cured 6 and 8 days and the results of unconfined compression tests $(U C)$ were shown in Fig. 3. The average of UC strength of the 6 days cured specimens were found as $3.1 \mathrm{~N} / \mathrm{mm}^{2}$. The UC strength value reaches to 5.7 $\mathrm{N} / \mathrm{mm}^{2}$ that is an average of three specimens cured for 8 days. These unconfined compressive strength values are very high even for short time of curing compared to 28 days. It means that, there is no need for subbase and base layer over the stabilized layer. An asphalt cover at a certain thickness can be chosen and applied over the stabilized layer according to these laboratory test results for a typical road cross section.

\section{Conclusions}

Mineral admixtures are becoming more popular in recent decades. The use of recycled materials as concrete ingredients has been gaining popularity because of increasingly stringent environmental legislation, and the discovery that such materials often have complementary and valuable properties. Various areas of application were identified and tested by Novocrete ${ }^{\circledR}$. Some of the selected applications are: Use of Novocrete ${ }^{\circledR}$ and Cement blended soil as pavement layer for highways and rural roads, use of Novocrete ${ }^{\circledR}$ and Cement blended soil layer below track underlays for rail roads on weak formation and also as track underlays for high speed train networks, Stabilization of embankments, construction of heavy load bearing pads for Port and other industries, storage areas for iron ores and other stack yards, etc., construction of pavements on soft soils, usage of recyclable aggregates and old asphalt pavement aggregate, etc..

In the applications usually $120-180 \mathrm{~kg}$ cement were used for $1 \mathrm{~m}^{3}$ of soil with a $2 \%$ of cement amount of binder NovoCrete ${ }^{\circledR}$ material for the stabilization. The results of a plate loading test in a road construction site shows $0,7 \mathrm{~mm}$ deformation which is very small under $7 \mathrm{~kg} / \mathrm{cm}^{2}$ loading. The modulus of subgrade reaction increase to 1322 $\mathrm{MN} / \mathrm{m}^{3}$ and $1666 \mathrm{MN} / \mathrm{m}^{3}$ The soaked CBR values for stabilized soils increase from $15-22 \%$ to 224 $239 \%$. According to these data weak subgrade soil can be used as a base or sub base after the modification. The UC strength value reaches to 5.7 $\mathrm{N} / \mathrm{mm}^{2}$ that is an average of three specimens cured for 8 days. These unconfined compressive strength values are very high even for short time of curing compared to 28 days. It also means that, there is no need for subbase and base layer over the stabilized layer. An asphalt cover at a certain thickness can be chosen according to this laboratory test results is enough for a typical road cross section. In place stabilization will have many advantages. The potential reduction in the need for quarried materials will help conserve natural resources. The use of on-site or nearby materials in fills, will significantly reduce transportation costs and provide both economic and environmental benefits

\section{References}

[1] Kavak A, Baykal G. "Long-term behavior of lime-stabilized kaolinite clay”, Environ Earth Sci 66:1943-1955, 2012

[2] Kavak A, Akyarlı A "A field application for lime stabilization". Engineering Geology 51-6:987-997, 2007

[3] Raymond N. Yong ${ }^{a}$, Vahid R. Ouhadi', "Experimental study on instability of bases on natural and lime/cement-stabilized clayey soils", Applied Clay Science Volume 35, Issues 3-4, February 2007, Pages 238-249

[4] Kiran B. Biradar, U. Arun kumar, Dr.PVV Satyanarayana, "Influence of Steel Slag and Fly Ash on Strength Properties of Clayey Soil: A Comparative Study, International Journal of Engineering Trends and Technology (IJETT) - Volume 14 Number 2 - Aug 2014

[5] IA Sulieman, MA Siddig, AA Elbadawi, Structural, 2008 "Optical and Electrical properties of Novocrete Material, neelain.edu.sd

[6] Bowles JE,"Engineering properties of soils and their measurements", 4th edition. McGraw-Hill, NY, 1992

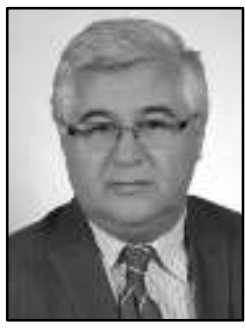

NovoCrete ${ }^{\circledR}$ is a patented new binder product. It improves the effect of cement stabilization by decreasing the rigidity and increase the strength of the cement for road materials. After use of this binder, mostly there will be no need for base and subbase author: Aydin Kavak 